\begin{tabular}{|l|l|l|l|l|l|l|}
\hline InterteXto & Uberaba & UFTM & $\begin{array}{l}\text { v. } 4 \\
\text { n. } 2\end{array}$ & p. 50-67 & 2011 - jul. / dez. & ISSN 1981-0601 \\
\hline
\end{tabular}

\title{
BAKHTIN E O CRONOTOPO: UMA ANÁLISE CRÍTICA
}

\section{BAKHTIN AND THE CHRONOTOPE: A CRITICAL ANALYSIS}

Ozíris Borges Filho ${ }^{1}$

RESUMO: Neste artigo, analisamos a proposta bakhtiniana a respeito do cronotopo, levantando algumas hipóteses para o estudo desse conceito à luz da Teoria Literária contemporânea. Analisamos também alguns autores, principalmente nacionais, que fizeram uma resenha a respeito desse mesmo conceito em Bakhtin.

PALAVRAS-CHAVE: Bakhtin; espaço; tempo; cronotopo.

ABSTRACT: Cet article analyse la proposition de Bakhtine sur le chronotope. Nous avons également soulever quelques hypothèses pour l'étude de ce concept à la lumière de la théorie littéraire contemporaine. Nous avons analysé aussi certains auteurs, notamment nationaux, qui a fait un examen sur ce même concept dans Bakhtine.

KEYWORDS: Bakhtine; space; temp; chronotope.

Quanto à relação entre o objeto percebido e minha percepção, ela não os liga no espaço e fora do tempo: eles são contemporâneos. (Merleau Ponty. Fenomenologia da percepção, p. 357)

Entre 1937 e 1938, Bakhtin escreveu o texto Formas de tempo e de cronotopo no romance - ensaios de poética histórica(daqui em diante FTCR). Em 1973, ele acrescentou um texto ao final daquele primeiro a que chamou de "Observações finais". Esse ensaio aparece no livro Questões de literatura e estética publicado no Brasil, pela primeira vez, pela editora da UNESP em 1988, segundo Campos (2009, p.115). A respeito desse livro Campos(2009, p. 113) traz a seguinte informação importante:

O conjunto de ensaios, escrito entre 1924 e 1941, com um acréscimo em 1973, foi organizado pelo autor em Moscou nos

\footnotetext{
${ }^{1}$ Professor de Teoria da Literatura da UFTM. Líder do grupo de pesquisa NEL - Núcleo de Estudos Literários. Bolsista PET. oziris@oziris.pro.br , www.oziris.pro.br
} 


\begin{tabular}{|l|l|l|l|l|l|l|}
\hline InterteXto & Uberaba & UFTM & $\begin{array}{l}\text { v. 4 } \\
\text { n. } 2\end{array}$ & p. 50-67 & 2011 - jul. / dez. & ISSN 1981-0601 \\
\hline
\end{tabular}

últimos anos de sua vida, mas só publicado em 1975, depois de sua morte, sob o título Voprosy literatury $i$ estetiki: issledovaniia raznykl let (Problemas de literatura e de estética: estudos de vários anos). Estes ensaios são considerados por Brandist uma das contribuições mais influentes e valiosas para o estudo das línguas e literaturas européias.

E, mais adiante, complementa:

A leitura dos ensaios, de tamanhos e complexidades variadas, exige que o leitor tenha presente que eles foram produzidos pelo nômade Bakhtin que viveu em várias cidades russas: Neved, Vitebsk, Leningrado, Kustanai (no Cazaquistão), Saransk, Savelovo, novamente Saransk e depois Moscou. A essa longa peregrinação, somam-se problemas da primeira edição russa, uma vez que os editores retiraram muitas referências feitas aos lingüistas soviéticos contemporâneos, gerando para o leitor uma perda das relações com o contexto intelectual. (p. 113)

Esse artigo de CAMPOS(2009) é muito útil para a compreensão da recepção dos ensaios que foram reunidos nesse livro de Bakhtin. Remetemos a ele os leitores interessados nessa perspectiva.

Apesar de ser um texto publicado há mais de cinqüenta anos, ele ainda é atual e foi pouco tratada pela Teoria da Literatura. Nessa linha de raciocínio cumpre também refletirmos sobre as palavras de MITTERAND(1990, p. 89)

Les observations de Bakhtine, pour la plupart anciennes d'une cinquantaine d'années, mais qui ont conservé tout leur intérêt, se présentent en ordre assez dispersé. (...) Bakhtine ne se préoccupe pas de systématiser sa théorie, qui reste hétérogène, éclatée en multiples définitions et en multiples exemples, usant d'une terminologie variable et faisant allusion à une classification des genres et à une théorie du dialogisme qu'il faut aller chercher ailleurs. Tout cela n'en diminue nullement l'importance: chacun doit seulement tenter de reconstruire la vision cohérente qui sous-tend ces pages profondes et denses. (p. 89)

Ao que se sabe, o teórico russo foi o primeiro a trazer para os estudos literários a idéia de uma abordagem indissociável entre o espaço e o tempo. A essa junção das duas categorias da narrativa, ele chamou de cronotopo. 


\begin{tabular}{|l|l|l|l|l|l|l|}
\hline InterteXto & Uberaba & UFTM & $\begin{array}{l}\text { v. 4 } \\
\text { n. } 2\end{array}$ & p. 50-67 & 2011 - jul. / dez. & ISSN 1981-0601 \\
\hline
\end{tabular}

Atente-se para o fato de que Bakhtin, ao contrário do que afirma FIORIN (2006, p. 133), não é o criador do conceito de cronotopo. Como escreve o próprio autor russo: "Esse termo é empregado nas ciências matemáticas e foi introduzido e fundamentado com base na teoria da relatividade (Einstein)." (p. 211) Assim, Bakhtin transpõe o conceito para a literatura, naturalmente fazendo as adaptações para o campo literário. Como afirma o autor russo, ele transpõe o conceito "para a crítica literária quase como uma metáfora (quase, mas não totalmente)."(p. 211) Em AMORIM(2006, p. 102), encontramos também a ratificação dessa mesma interpretação:

Bakhtin toma-o (o conceito de cronotopo) emprestado à matemática e à teoria da relatividade de Einstein para exprimir a indissolubilidade da relação entre o espaço e o tempo, sendo este último definido como a quarta dimensão do primeiro.

MACHADO(1995, p. 248) também encara da mesma forma: "O termo cronotopo Bakhtin encontrou na física, ou melhor, na teoria da relatividade de Einstein, com a qual ele entra em contato no final dos anos 20."

Apesar de ter sido o primeiro a trazer tal conceito para os estudos literários cumpre salientar que as relações espaço-tempo estavam na ordem do dia nos anos vinte. É o que afirmam HOLQUIST e CLARK(2004, p. 295)

\footnotetext{
Bakhtin estava obcecado pela interconexão de espaço e tempo. Na década de 20, esse interesse era amplamente compartilhado pelos intelectuais soviéticos. Einstein e Bergson achavam-se particularmente em moda. Mas nas explorações iniciais empreendidas por Bakhtin na questão, ele não se apoiou nestes dois pensadores, mas em outros, sobretudo em Kant e nos neokantianos.
}

Além do texto FTCR acima mencionado, o estudioso russo disserta sobre o cronotopo no texto O romance de educação na história do Realismo (daqui em diante REHR) que se encontra no livro Estética da criação verbal. Esse texto foi escrito entre 1936 e 1938. Portanto, é provável que ele tenha sido escrito na seqüência do primeiro que mencionamos, formando um todo. Esses são os dois únicos textos em que Bakhtin trabalha explicitamente com a 


\begin{tabular}{|l|l|l|l|l|l|l|}
\hline InterteXto & Uberaba & UFTM & $\begin{array}{l}\text { v. } 4 \\
\text { n. } 2\end{array}$ & p. 50-67 & 2011 - jul. / dez. & ISSN 1981-0601 \\
\hline
\end{tabular}

noção de cronotopo. Também para Campos(2009, p. 136)

... é preciso lembrar que as noções teóricas do cronotopo estão presentes também no ensaio "O romance da educação e sua importância na história do realismo" escrito na mesma época (1936-1938). Nesse trabalho, Bakhtin analisa o romance de Goethe, que, para ele, coloca-se ao lado de Dostoiévski e Rabelais.

Note-se porém que nesse texto, REHR, Bakhtin não acrescenta nenhum cronotopo novo nem amplia o conceito. O objetivo é ratificar as idéias anteriores, analisando principalmente a obra de Goethe, mais especificamente Os anos de aprendizado de Wilhelm Meister. Para MACHADO (1995, p. 278279)

Antes de mais nada é preciso lembrar que Goethe não criou um novo cronotopo. Aos olhos de Bakhtin, a obra de Goethe configura um metacronotopo, representa a possibilidade de reconstrução do conceito de gênero.

No plano da Teoria da Literatura, Bakhtin foi o primeiro a propor essa abordagem indissociável entre espaço e tempo na análise literária além de ter sido o introdutor do neologismo cronotopo no âmbito dos estudos literários. Daí vem também a importância dessa sua contribuição fundamental. Segundo MITTERAND(1990, p. 102)

La théorie bakhtinienne du chronotope est une contribution fondamentale à l'étude des composantes du roman et, au-delà, à l'étude des genres. Elle montre le temps à l'œuvre dans l'espace et l'espace à l'œuvre dans le temps, solidairement. On peut et on doit en dériver toutes sortes d'applications, y compris dans l'ordre du langage. Elle renouvelle profondément notre réflexion sur al relation du roman et de l'histoire, de la littérature et de l'évolution des sociétés. Elle permet de comprendre pourquoi un grand roman, comme Germinal, ou l'Education sentimentale, ou Les misérables, peut être plus riche de savoir, sur le " tout de la vie », qu'une pure spéculation philosophique ou une encyclopédie historique ou scientifique. Elle aide l'analyse littéraire à poser de vraies et grandes questions aux textes. 


\begin{tabular}{|l|l|l|l|l|l|l|}
\hline InterteXto & Uberaba & UFTM & $\begin{array}{l}\text { v. 4 } \\
\text { n. } 2\end{array}$ & p. 50-67 & 2011 - jul. / dez. & ISSN 1981-0601 \\
\hline
\end{tabular}

Dentro do projeto bakhtiniano de conceituar o espaço-tempo do romance, nota-se que o texto FTCR, é o mais denso e também é aquele em que a concepção de cronotopo foi mais profundamente abordada.

Em uma pequena introdução ao texto FTCR, Bakhtin divide-o em dez itens, a saber: I - O romance grego; II - Apuleio e Petrônio; III - Biografia e autobiografia antigas; IV - O problema da inversão histórica e do cronotopo folclórico; V - O romance de cavalaria; VI - Funções do trapaceiro, do bufão e do bobo no romance; VII - O Cronotopo de Rabelais; VIII - Fundamentos folclóricos do cronotopo de Rabelais; IX - O cronotopo idílico no romance; X Observações finais.

Em sua apresentação, Bakhtin começa pela afirmação de que a Literatura assimilou de maneira complexa o tempo e o espaço bem como o indivíduo histórico que se revela nessas duas categorias. Afirma ainda que cada sociedade, dadas as suas condições históricas, assimilou parte dessa realidade e forjou gêneros textuais de acordo com essa assimilação. É nesse sentido que HOLQUIST e CLARK(2004, p.296) afirmam que Bakhtin

Insiste igualmente na natureza histórica de tais conceitos, no
fato de que, em épocas diferentes, combinações diferentes de
espaço e tempo foram utilizadas a fim de moldar a realidade
externa. A mais paradigmática expressão de cronótopos
passados encontra-se em textos literários. Uma vez que
moldam mundos inteiros, os autores são inelutavelmente
forçados a empregar as categorias organizadoras dos mundos
que eles próprios habitam.

Realmente, como afirmam os autores americanos, é inevitável que o artista é influenciado pelo espaço-tempo em que vive e que essa influência aparece na obra artística. No entanto, devemos ter em mente igualmente que a representação dessa influência cronotópica é relativa a cada autor. Em outras palavras, há autores que compreendem melhor a importância de seu próprio cronotopo e conseguem recriá-lo na obra esteticamente de maneira intensa, outros nem tanto. Parece-nos que esse também é o sentido das palavras de AMORIM(2006, p. 111) quando afirma que 


\begin{tabular}{|l|l|l|l|l|l|l|}
\hline InterteXto & Uberaba & UFTM & $\begin{array}{l}\text { v. } 4 \\
\text { n. } 2\end{array}$ & p. 50-67 & 2011 - jul. / dez. & ISSN 1981-0601 \\
\hline
\end{tabular}

Para terminar, gostaríamos de indicar um outro aspecto dos conceitos aqui trabalhados.como ocorre freqüentemente no pensamento bakhtiniano, os conceitos de exotopia e cronotopo parecem estar sujeitos a uma gradação. Há textos mais cronotópicos do que outros.

Tanto no texto FCTR quanto em REHR, vemos, pelas análises de Bakhtin, que há textos mais cronotópicos que outros. É nesse sentido que ele afirma em REHR que "Na literatura mundial, um dos ápices da visão do tempo histórico é atingido por Goethe." Ora, se existe o ápice, certamente, existem aqueles que estão mais próximos dele e aqueles que estão mais distanciados, portanto, gradação.

Para Bakhtin(1998, p. 211), cronotopo é a "interligação fundamental das relações temporais e espaciais, artisticamente assimiladas em literatura." Salienta ainda dois pontos. Primeiro, o caráter indissociável do espaço-tempo na idéia de cronotopo. Segundo, o cronotopo é uma categoria conteudísticoformal da literatura. Esse segundo aspecto, na maioria das vezes, passa despercebido pelos estudiosos, isto é, para o teórico russo, cronotopo é tanto conteúdo quanto estrutura, tanto verticalidade quanto horizontalidade. Veja-se, a título de exemplo, o seguinte trecho do mesmo texto bakhtiniano: "o próprio espaço intensifica-se, penetra no movimento do tempo, do enredo e da história."(p.211) Note-se como o autor justapõem texto e contexto: espaço, tempo, enredo, história. Para ele, "o cruzamento de séries e a fusão de sinais caracterizam o cronotopo artístico". Ainda nesse sentido formal, o autor russo salienta que

Com muita freqüência o cronotopo do encontro exerce, em literatura, funções composicionais: serve de nó, às vezes, ponto culminante ou mesmo desfecho (final) do enredo. ( $p$. 222)

Note-se a citação das divisões clássicas da fábula: nó, clímax e desfecho. Tal fato evidencia a preocupação formal com o cronotopo apesar de ser pouco explorado pelo autor. 


\begin{tabular}{|l|l|l|l|l|l|l|}
\hline InterteXto & Uberaba & UFTM & $\begin{array}{l}\text { v. 4 } \\
\text { n. } 2\end{array}$ & p. 50-67 & 2011 - jul. / dez. & ISSN 1981-0601 \\
\hline
\end{tabular}

Mesmo sem desenvolver o pensamento, o autor associa o cronotopo aos gêneros literários, dizendo inclusive que as variedades de gêneros são determinadas por ele. Segundo HOLQUIST \& CLARK(2004, p. 293),

O gênero é, para ele, um raio $X$ de uma visão de mundo específica, uma cristalização dos conceitos peculiares a um dado tempo e a um dado estrato social em uma sociedade determinada. Um gênero, por conseguinte, encarna uma idéia historicamente específica do que significa ser humano.

E, mais à frente, os estudiosos americanos afirmam que "Ao focalizar de passagem que um cronótopo em particular define um gênero ou um subgênero particular, Bakhtin faz remontar o advento do romance à Grécia helenística." ( $p$. 298)

O texto bakhtiano em foco é povoado de idéias instigantes, propondo novas abordagens do texto literário. No entanto, perguntamos, será que o texto bakhtiano ainda é atual depois de mais de setenta anos de sua publicação? Será que a Teoria da Literatura, após todos esses anos, não teria nada a acrescentar à idéia pioneira do cronotopo? Em nossas reflexões, pretendemos resenhar e questionar o texto bakhtiano. Pretende-se mostrar que se pode (e se deve), hoje, com as novas teorias literárias sobre o espaço e o tempo, levar a proposta de Bakhtin a um patamar superior àquele em que foi originalmente concebida. Esse é o principal objetivo de nossas reflexões.

Num primeiro momento é interessante verificar como a bibliografia crítica bakhtiniana nacional e alguma estrangeira pouco trata do cronotopo. Geralmente, temos um capítulo sobre o romance e, nesse capítulo, mencionase o cronotopo como um subitem. A exceção é a obra de MACHADO (1995), uma das primeiras a se debruçar sobre a obra de Bakhtin em nosso país.

Quais seriam as razões desse pouco interesse pelo conceito bakhtiniano de cronotopo? Acreditamos que três são as principais razões. Primeira, é que a maior parte da bibliografia sobre Bakhtin produzida hoje em nosso país vem de lingüistas. Como Bakhtin trabalhou esse conceito, voltando-se exclusivamente 


\begin{tabular}{|l|l|l|l|l|l|l|}
\hline InterteXto & Uberaba & UFTM & $\begin{array}{l}\text { v. 4 } \\
\text { n. } 2\end{array}$ & p. 50-67 & 2011 - jul. / dez. & ISSN 1981-0601 \\
\hline
\end{tabular}

para o romance, apesar de mencionar a operacionalidade desse conceito para as outras artes, pode ser que essa primeira impressão tenha afastado os colegas da lingüística.

Uma possível segunda razão é o fato de os estudos literários hoje no Brasil privilegiarem uma abordagem temática quase sempre via Estudos Culturais. Assim, desavisados, esses estudiosos podem achar que a abordagem bakhtiniana do espaço-tempo seja estruturalista-formalista. Isso porque essas duas categorias da narrativa foram normalmente trabalhadas desse ponto de vista. Tal fato não deixa de ser irônico, pois, apesar de reconhecer o cronotopo como forma, a abordagem do teórico russo é eminentemente temática e histórica e, portanto, traria para os estudos culturais e temáticos da literatura grandes reflexões e novas perspectivas de análise.

Um terceiro ponto ainda deve ser levado em consideração. Trata-se da própria extensão do texto. São cento e cinqüenta e uma páginas do texto Formas de tempo e de cronotopo no romance - ensaios de poética histórica mais cinqüenta e cinco páginas do texto O romance de educação na história do Realismo. Como se vê, os dois textos formam um livro por si sós de alentadas duzentas e seis páginas.

Dessas três razões surgem as diferenças entre os intérpretes bem como alguns equívocos e superficialidade na leitura feita por eles desses dois textos bakhtinianos.

No texto FTCR e REHR, Bakhtin, segundo nossa leitura, aponta 10 cronotopos, a saber, do encontro, do caminho/estrada, da praça pública, mitológico/popular, mágico, do palco teatral, do castelo, do salão ou sala de visita, da cidadezinha, da soleira (limiar). Analisando-se alguns textos críticos que comentam o cronotopo, constatamos uma grande divergência entre eles na determinação de quantos e quais são os grandes cronotopos apontados pelo teórico russo em seu texto. FIORIN(2006, p. 134) afirma que analisará apenas o primeiro tipo de romance que é o grego e, portanto, aborda apenas um cronotopo: "Vamos, a título de exemplificação do estudo 


\begin{tabular}{|l|l|l|l|l|l|l|}
\hline InterteXto & Uberaba & UFTM & $\begin{array}{l}\text { v. 4 } \\
\text { n. } 2\end{array}$ & p. 50-67 & 2011 - jul. / dez. & ISSN 1981-0601 \\
\hline
\end{tabular}

bakhtiniano do cronotopo, expor as idéias de Bakhtin apenas a respeito de um dos cronotopos: do romance de aventura de provações." Campos(2009, p. 131132) aponta sete tipos de cronotopo: da aventura, da estrada, da praça pública, do entreato, do corpo, do idílio e o do autor e leitor. $\operatorname{AMORIM(2006,~p.~102)~é~a~}$ única autora da bibliografia que pesquisamos que coloca a palavra no plural e não no singular: cronotopos. É também a única que faz uma aproximação do conceito de cronotopo com o de exotopia, outro conceito bakhtiniano que aparece na antologia de ensaios Estética da criação verbal. Além dessas particularidades, também notamos na autora uma despreocupação em analisar criticamente os vários cronotopos propostos por Bakhtin. Ela cita apenas dois cronotopos, a saber, o da estrada e, brevemente, o do encontro. Ao que nos parece a autora concentrou-se mais na análise geral do conceito de cronotopo, comparando-o com o conceito de exotopia e aplicando esses conceitos na leitura que faz de alguns filmes e um quadro de Picasso. Nesse sentido, o texto soa um pouco superficial. Em HOLQUIST E CLARK(2004) o vocábulo aparece grafado como proparoxítona e não paroxítona na tradução de J. Guinsburg: cronótopo. Esses autores apontam cinco cronotopos: tempo de aventura, da vida cotidiana, o biográfico, do castelo e do salão. Esses dois últimos não são trabalhados pelos autores como os anteriores, mas apenas mencionados. Sem dúvida nenhuma, o trabalho de MACHADO(1995), dentro da bibliografia pesquisada, é o mais completo. Segundo ela (p. 256)

No romance grego, nas sátiras, na biografia e nas formas cronotópicas da renascença desenvolveram-se os grandes cronotopos do romance: a ventura, a provação, a metamorfose do indivíduo, o homem corporal e interior. Todos estes cronotopos se desenvolveram e permaneceram na constituição do romance europeu do século XIX e do século XX, ainda que Bakhtin não tenha se dedicado ao romance moderno.

Como vemos, para Machado quatro são os principais cronotopos, a saber: a aventura, a provação, a metamorfose do indivíduo(ou cronotopo da vida privada e do cotidiano), o homem corporal e interior. No decorrer do 


\begin{tabular}{|l|l|l|l|l|l|l|}
\hline InterteXto & Uberaba & UFTM & $\begin{array}{l}\text { v. } 4 \\
\text { n. } 2\end{array}$ & p. 50-67 & 2011 - jul. / dez. & ISSN 1981-0601 \\
\hline
\end{tabular}

capítulo, fala ainda em cronotopo biográfico e a vida na praça pública e também do cronotopo do idílio e da natureza.

Mas, afinal, quais são as principais características do conceito de cronotopo? Duas das características do cronotopo já podem ser percebidas pelo título do texto: Formas de tempo e de cronotopo no romance - ensaios de poética histórica. Para efeito didático, dividamos o título em duas partes, a primeira indo do início até a palavra "romance" e, a segunda, o restante. $\mathrm{Na}$ primeira parte, notamos que a idéia de tempo sobressai, pois ela aparece duas vezes. Como forma autônoma na própria palavra tempo e no neologismo cronotopo. Já o espaço aparece uma única vez no neologismo cronotopo. Por que será que Bakhtin dá essa ênfase? Porque para ele, mesmo que o cronotopo represente a indissociabilidade do espaço-tempo, o tempo é o princípio condutor?

O cronotopo tem um significado fundamental para os gêneros na literatura. Pode-se dizer francamente que o gênero e as variedades de gênero são determinadas justamente pelo cronotopo, sendo que em literatura o princípio condutor do cronotopo é o tempo. (BAKHTIN, 1998, p. 312)

Esse primeiro aspecto fica bem visível não só no título, mas também nas análises feitas pelo pensador russo. Em grande parte dos capítulos, ele analisa o tempo, relegando o espaço a segundo plano. Essa é a mesma leitura que faz MITTERAND(1990, p. 92) ao afirmar que "Le chronotope favori de Bakhtine est évidemment celui de l'histoire." Entretanto, cabe perguntar por que o tempo é mais importante que o espaço? Por que o tempo seria o princípio condutor do cronotopo? Infelizmente, o teórico russo não nos dá absolutamente nenhum argumento para essa afirmativa. Esse fato, naturalmente, depõe contra a assertiva de Bakhtin. Esse é outro ponto interessante em relação à bibliografia crítica que pesquisamos. Nenhum dos autores pesquisados questiona essa proposta bakhtiniana. Isso não é de se estranhar visto que o espaço, como diz FOUCAULT(1992, p. 158) 


\begin{tabular}{|l|l|l|l|l|l|l|}
\hline InterteXto & Uberaba & UFTM & $\begin{array}{l}\text { v. } 4 \\
\text { n. } 2\end{array}$ & p. 50-67 & 2011 - jul. / dez. & ISSN 1981-0601 \\
\hline
\end{tabular}

Seria necessário fazer uma crítica dessa desqualificação do espaço que vem reinando há várias gerações. Foi com Bergson, ou mesmo antes, que isso começou. O espaço é o que estava morto, fixo, não dialético, imóvel.

Em compensação, o tempo era rico, fecundo, vivo, dialético. A utilização de termos espaciais tem um quê de anti-história para todos que confundem a história com as velhas formas da evolução, da continuidade viva, do desenvolvimento orgânico, do progresso da consciência ou do projeto da existência. Se alguém falasse em termos de espaço, é porque era contra o tempo. É porque "negava a história", como diziam os tolos, é porque era "tecnocrata".

Só a partir dos anos sessenta é que a teoria começou a questionar essa concepção a que se refere Foucault e isso veio sendo feito lentamente. A nosso ver, não se justifica propor o tempo como princípio condutor do cronotopo. Pensamos mais numa relação dialética e equânime entre essas duas categorias. Com efeito, já os gregos afirmaram que nada existe fora das categorias de espaço e de tempo. Se imaginarmos alguém ou algo, esse ser obrigatoriamente estará situado em algum lugar em determinado tempo. Mesmo que essas categorias não apareçam explicitamente em algum trecho do texto literário, elas são sempre pressupostas. Além disso, por uma questão de lógica, a idéia de indissociabilidade pressupõe a igualdade de importância entre espaço e tempo.

$\mathrm{Na}$ segunda parte do título, Ensaios de poética histórica, percebe-se uma segunda característica do cronotopo de acordo com Bakhtin. Depreendese essa segunda característica do vocábulo "histórica". Esse adjetivo pode ser interpretado de duas formas. Primeiro ele significa a proposta bakhtiniana de analisar a forma romance desde os seus primórdios na Grécia até o Renascimento com Rabelais e, ainda, cita Zola, Balzac e Dostoievski. Portanto, trata-se de um estudo histórico que mostra como determinado cronotopo, por exemplo, o da praça pública, foi modificando-se e/ou sendo substituído por outro tipo. No entanto, essa preocupação com a história também se manifesta na imagem de homem que aparece na interpretação cronotópica. Assim, os 


\begin{tabular}{|l|l|l|l|l|l|l|}
\hline InterteXto & Uberaba & UFTM & $\begin{array}{l}\text { v. } 4 \\
\text { n. } 2\end{array}$ & p. 50-67 & 2011 - jul. / dez. & ISSN 1981-0601 \\
\hline
\end{tabular}

cronotopos presentes em determinado romance manifestam a imagem de homem que circulava na sociedade em que o texto foi produzido. Para MACHADO(1995, p. 281)

\begin{abstract}
O processo de construção da imagem cronotópica no romance revela como Bakhtin entendeu os processos de construção do enredo em sua estreita vinculação com o desempenho do herói. Juntam-se dois temas fundamentais da teoria de Bakhtin: a representação do homem (heróis) e de suas ações.
\end{abstract}

Essa é a segunda característica do cronotopo e Bakhtin não cansa de afirmar isso durante todo o texto. Por isso, ele afirma que o cronotopo é uma categoria conteudístico-formal e histórica. Em outros termos, o cronotopo se aplica tanto numa análise intrínseca quanto extrínseca, tanto numa análise temático-estrutural quanto numa análise histórica. Em verdade, a proposta bakhtiniana é, digamos, holística, na medida em que tenta unir a análise formal à análise conteudística. Essa é mais uma prova da genialidade do autor russo. Num momento em que a maioria dos teóricos do chamado Formalismo Russo propunha uma análise totalmente imanente, Bakhtin tenta aliar o intrínseco com o extrínseco. Infelizmente, no entanto, apesar de sua proposta, na prática, o autor faz uma análise mais temática que estrutural. Em outras palavras, nos exemplos citados em seus textos, Bakhtin não faz uma abordagem estrutural do cronotopo, mesmo considerando-o uma categoria "conteudístico-formal".

Outra característica interessante dada ao cronotopo por Bakhtin é o fato de o cronotopo ser um determinante na classificação dos gêneros literários. $E$, para MACHADO(1995, p. 251), o cronotopo não é apenas importante para os gêneros literários:

O gênero é um conceito nuclear da poética histórica de Bakhtin não só porque a partir dele é possível reconstituir a imagem espaço-temporal da representação, mas porque o gênero orienta todo o uso da linguagem, como Bakhtin demonstrou teoricamente em seu estudo sobre os gêneros discursivos. O gênero é, assim, princípio construtivo elementar da estética da criação verbal." 


\begin{tabular}{|l|l|l|l|l|l|l|}
\hline InterteXto & Uberaba & UFTM & $\begin{array}{l}\text { v. 4 } \\
\text { n. } 2\end{array}$ & p. 50-67 & 2011 - jul. / dez. & ISSN 1981-0601 \\
\hline
\end{tabular}

Seja como for, no texto FTCR, percebe-se que a mudança cronotópica estabelece diferentes gêneros literários. Assim, de acordo com o cronotopo temos Romance grego, Romance biográfico, Romance de cavalaria, Romance idílico, etc.

De acordo com esse ponto, verifica-se uma outra ironia devido ao esquecimento desse texto em foco pelos estudiosos brasileiros. No Brasil, o tema dos "gêneros textuais" é um dos mais evidentes atualmente, no entanto pouquíssimos estudos nesse campo levam em conta o cronotopo.

Como dissemos anteriormente, o capítulo décimo do texto FTCR, intitulado "Observações finais", foi escrito em 1973. Portanto, trinta e cinco anos depois dos outros nove capítulos.

Essas considerações são muito importantes, no entanto, muitos comentadores de Bakhtin passaram superficialmente por ele ou sequer 0 mencionam. As "Observações finais" podem ser divididas em três grupos de idéias. Uma primeira idéia bastante interessante nesse último texto diz respeito à ampliação do conceito de cronotopo para as outras artes. Sem analisar qualquer outra obra de arte que não a literatura, Bakhtin afirma que o conceito se aplica a todas as artes. Segundo ele:

Em arte e em literatura, todas as definições espaço-temporais são inseparáveis umas das outras e são sempre tingidas de um matiz emocional. (...) A arte e a literatura estão impregnadas por valores cronotópicos de diversos graus e dimensões. Cada momento, cada elemento destacado de uma obra de arte são estes valores. (p. 349)

Dessa maneira, o teórico russo abre perspectivas interessantes para todos os críticos de arte não somente para os críticos literários. Analisando a abordagem bakhtiniana, podemos ter idéias bem precisas do que seria uma cronotopanálise em outras artes. Por isso, parece-nos equívoca a afirmativa de AMORIM(2006. p. 95) quando diz que o cronotopo "foi concebido no âmbito estrito do texto literário;...".

A segunda perspectiva interessante nas "Observações finais" acontece 


\begin{tabular}{|l|l|l|l|l|l|l|}
\hline InterteXto & Uberaba & UFTM & $\begin{array}{l}\text { v. } 4 \\
\text { n. } 2\end{array}$ & p. 50-67 & 2011 - jul. / dez. & ISSN 1981-0601 \\
\hline
\end{tabular}

quando o autor faz uma síntese de idéias anteriores e também explora algumas dessas idéias, incluindo dois novos cronotopos interessantes, o do castelo e o do salão/sala de visitas. Já num terceiro grupo de idéias o teórico russo introduz novas possibilidades a respeito do cronotopo como aquelas que defendem a inclusão do autor e do leitor naquele conceito.

Para Bakhtin, o cronotopo "determina a unidade artística de uma obra de arte" e lhe confere inúmeros matizes emocionais. Por exemplo, o cronotopo do encontro poderá estar marcado por conotações sentimentais do tipo "foi bom/foi ruim". O autor lança ainda uma pergunta: "Qual o significado dos cronotopos analisados?" São dois esses significados, um temático e outro figurativo. É temático porque o cronotopo é o gerador de todos os temas presentes na obra. É figurativo porque o cronotopo é a representação real do espaço-tempo. É o que poderíamos chamar hoje de "efeito de real" ou de "referente", dependendo do teórico que invocarmos. Para MACHADO(1995, p. 255)

Ao representar o homem vivendo situações, o cronotopo tornase o centro organizador dos principais acontecimentos temáticos do romance. É aí que os nós do enredo são feitos e desfeitos. As ações nunca são imagens vazias mas encarnam a dimensão do tempo e do lugar em que acontecem. Todos os elementos abstratos do romance - as generalidade filosóficas e sociais, as idéia, as análises das causas e dos efeitos gravitam ao redor do cronotopo, graças ao qual "se enchem de carne e osso" (BAKHTIN, 1988, p. 355-6).

O cronotopo é também a principal característica da imagem literária. Toda imagem literária é essencialmente cronotópica. Para o teórico, Lessing, em seu estudo sobre o Laocoonte, foi o primeiro a estabelecer esse princípio. Para exemplificar esse fato, Bakhtin(1998, p. 356) cita a passagem do autor alemão em que este cita Homero: em vez de descrever a beleza de Helena, o autor grego mostra o efeito dessa beleza nas outras personagens quando Helena entra num salão. 


\begin{tabular}{|l|l|l|l|l|l|l|}
\hline InterteXto & Uberaba & UFTM & $\begin{array}{l}\text { v. } 4 \\
\text { n. } 2\end{array}$ & p. 50-67 & 2011 - jul. / dez. & ISSN 1981-0601 \\
\hline
\end{tabular}

Tudo o que é estático-espacial não deve ser descrito de modo estático, mas deve ser incluído na série temporal dos acontecimentos representados e da própria narrativa-imagem. Assim, no famoso exemplo de Lessing, a beleza de Helena não é descrita por Homero, é mostrado, porém, seu efeito sobre os velhos troianos, efeito este que é revelado numa série de movimentos e ações dos velhos. A beleza é introduzida numa cadeia de acontecimentos representados e ao mesmo tempo se apresenta não como o objeto de uma descrição estática, mas como o objeto de uma narrativa dinâmica.

Ou seja, não há uma parada descritiva, mas uma mistura de ação e descrição, não há mais os blocos descritivos. Essa técnica será chamada, bem depois, de ambientação dissimulada por Osman Lins (1976).

Nas "Observações finais", o autor russo afirma que abordou apenas os grandes cronotopos, mas que existem infinitos. Para ele, "cada tema possui o seu próprio cronotopo".

Além disso, o caráter do cronotopo é dialógico. O cronotopo literário estabelece um diálogo com o autor, com o leitor, com os intérpretes e com os ouvintes. É interessante notar aqui a entrada das entidades do leitor e do autor que não apareceram antes, no texto escrito entre 1937 e 1938. Segundo CAMPOS(2009, p. 136) Bakhtin

Reconhece a importância desse conceito para uma produção da história do romance e da cultura e propõe uma questão: 'de que ponto espaço-temporal observa o autor os acontecimentos por ele representados?', o que o leva a distinguir entre o tempo representado da obra e o tempo real que representa? (grifos da autora)

Finalizando seu texto, Bakhtin se pergunta quais são os limites da análise cronotópica. No entanto, precavidamente, ele não responde, deixando a resposta para a posteridade. Para ele "O quanto esta abordagem proposta no nosso trabalho seja importante e fecunda, só poderá ser determinado no futuro pela evolução dos estudos literários."(p. 361)

Como vimos, e o próprio autor afirma, ele apenas cuidou dos grandes cronotopos. Desse ponto de vista, a análise bakhtiniana é geral, isto é, ela não 


\begin{tabular}{|l|l|l|l|l|l|l|}
\hline InterteXto & Uberaba & UFTM & $\begin{array}{l}\text { v. } 4 \\
\text { n. } 2\end{array}$ & p. 50-67 & 2011 - jul. / dez. & ISSN 1981-0601 \\
\hline
\end{tabular}

abarca os cronotopos menores que povoam a obra literária. O próprio autor ao apontar o cronotopo do salão ou sala de visitas em Balzac, afirma que este não é o único, mas apenas "um dos lugares", e aponta que na obra desse escritor francês existem inúmeros cronotopos tais como: "casas, ruas, cidade, paisagem rural." Mas o autor não analisa esses cronotopos "menores". Como seriam essas análises de espaço menores e pontuais na obra literária?

Nesse aspecto, falta-nos um modelo teórico para a aplicação da metodologia bakhtiniana. Como espaço e tempo são indissolúveis, há inúmeros cronotopos num mesmo texto literário. Como determiná-los? Selecionar os mais presentes dentro da obra literária, corpus do trabalho de análise? Como analisá-los do ponto de vista de uma microanálise e não de sua generalidade?

Além disso, cumpre pensarmos a respeito das afirmações de MITTERRAND(1990, p. 103) e que, parece-nos, passaram despercebidas.

Mais il est clair qu'au chronotope Bakhtinien manque la double dimension du contenu symbolique et de la forme sémiotique. La relation que Bakhtine institue être l'œuvre et l'histoire par le moyen du chronotope est trop unilatérale. II resterait sans doute maintenant à la médiatiser et à l'affiner, en tenant compte non seulement du temps-espace dans l'œuvre, mais aussi du temps-espace de l'œuvre.

Com efeito, para além da estrutura (la forme sémiotique) será que a abordagem bakhtiniana abrange satisfatoriamente o conteúdo simbólico da obra literária?

E o que dizer a respeito das propostas de análise do espaço e do tempo que surgiram a partir dos anos sessenta com o estruturalismo. Já que o cronotopo possui uma parte formal, como aliar essas propostas estruturais mais recentes com a metodologia bakhtiniana? É possível? Quais seus limites?

Segundo MACHADO(1995, p. 243)

Nas teorias surgidas sob o impacto dos vários estruturalismos, o tempo é focalizado através da organização lógica dos episódios narrativos. Se narrar é relatar o passado, há que se considerar, pelo menos, dois planos temporais: o tempo do 


\begin{tabular}{|l|l|l|l|l|l|l|}
\hline InterteXto & Uberaba & UFTM & $\begin{array}{l}\text { v. } 4 \\
\text { n. } 2\end{array}$ & p. 50-67 & 2011 - jul. / dez. & ISSN 1981-0601 \\
\hline
\end{tabular}

narrar a história (o discurso) e o tempo do narrado (o vivido). Afinal, os eventos passados são transmitidos por uma voz presente. A teorização sobre o tempo passa, necessariamente, pelo confronto destes dois planos.

Da mesma forma que a teoria nos anos setenta chegou a essa divisão entre o tempo do narrar e o tempo do narrado, contemporaneamente também se consideram dois planos espaciais na construção da obra: o espaço do narrar e o espaço do narrado. Assim, a questão fica ainda mais instigante: como aproximar as teorias estruturalistas a respeito do espaço-tempo da narração e do espaço-tempo da narrativa com a proposta do cronotopo? Em que a proposta de Bakhtin poderia acrescentar na proposta estruturalista?

Acreditamos que a Teoria da Literatura se encontra num momento em que já pode deixar a abordagem exclusivamente temporal ou exclusivamente espacial para passar para uma abordagem espaço-temporal da obra literária. Aliás, essa abordagem unilateral, por assim dizer, já fora criticada por MITTERAND(1990, p. 89)

On a vu paraître, ces dernières années, de nombreux ouvrages et articles sur les lieux romanesques. Mais bien rares sont les tentatives de saisit ensemble, dans leur connexions mutuelles, le temps et l'espace. C'est dire le mérite des Mikhaïl Bakhtine sur le chronotope, c'est-à-dire, selon ses propres termes, sur «ce qui se traduit littéralement par temps-espace: la corrélation essentielle des rapports spatio-temporels, telle qu'elle a été assimilée par la littérature.

Parece-nos que esse é o estado atual da questão. Como desconhecemos qualquer trabalho que tenha proposto algo similar, urge que a teoria da literatura enverede por esse caminho. Acreditamos que uma metodologia de análise literária que surgisse a partir daí, seria bastante benéfica para a Teoria da Literatura.

\section{Referências}

BAKHTIN, Mikhail. Estética da criação verbal. São Paulo: Martins Fontes, 


\begin{tabular}{|l|l|l|l|l|l|l|}
\hline InterteXto & Uberaba & UFTM & $\begin{array}{l}\text { v. } 4 \\
\text { n. } 2\end{array}$ & p. 50-67 & 2011 - jul. / dez. & ISSN 1981-0601 \\
\hline
\end{tabular}

1997.

Questões de literatura e estética. São Paulo: Unesp,

1998.

AMORIM, Marília. Cronotopo e exotopia In BRAIT, Beth (org.). Bakhtin outros conceitos-chave. São Paulo: Contexto, 2006.

CAMPOS, Maria Inês Batista. Questões de literatura e de estética: rotas bakhtinianas In BRAIT, Beth (org.). Bakhtin - dialogismo e polifonia. São Paulo: Contexto, 2009.

FIORIN, José Luiz. Introdução ao pensamento de Bakhtin. São Paulo: Ática, 2006.

FOUCAULT, Michel. Sobre a Geografia. In Microfísica do poder. Rio de Janeiro: Graal, 1992.

HOLQUIST, Michael \& CLARK, Katerina. Mikhail Bakhtin. São Paulo: Perspectiva, 2004.

LINS, Osman. Lima Barreto e o espaço romanesco. São Paulo: Ática, 1976. MACHADO, Irene. A voz e o romance. São Paulo: Imago, 1995. MITTERAND, Henri. Chronotopies romanesques: Germinal. In Poétique revue de théorie et d'analyse littéraires, n 81, 1990. 